\title{
Biochar: a potential soil ameliorant for sustainable land, agriculture and environmental development
}

\author{
Sanat Dwibedi ${ }^{1}$, VC Pandey ${ }^{2}$, and Donakonda Divyasree ${ }^{1}$ \\ ${ }^{1}$ Odisha University of Agriculture and Technology \\ ${ }^{2}$ Babasaheb Bhimrao Ambedkar University
}

April 19, 2021

\begin{abstract}
Biochar or pyrogenic carbon, obtained from thermo-chemical conversion of biomass in an anaerobic or oxygen limited environment has been in use in agriculture since long back to Neolithic era. Its unique soil ameliorating properties, render it suitable for environmental remediation as well as sustainable crop production. It improves soil physicochemical properties and plant nutrient availability, facilitates biodiversity, and reduces emission of greenhouse gases, thereby subsiding global warming. Application of biochar reduces soil erosion, improves soil hydrological properties, and soil microbial dynamics. It has synergistic effects on plant growth, disease-pest resistance, and crop yield per unit area and time. Due to its soil ameliorative effects, and soil and water conserving ability, it can very well be used in organic farming, pemaculture, dryland farming, conservation agriculture, and land remediation. Cheaper production cost, simple and easy pyrolytic technologies, easy availability of feedstock and bio-wastes in many developing countries and its long-term effects in soil not only build up soil carbon pool but also help support small and marginal farmers in resource-rich but economically deprived countries for sustainable agriculture and environment. In this review, efforts have been made to elucidate various methods of biochar synthesis, its characteristics and effects on soil properties, and plant growth and development, its role in sustainable agriculture and remediation of the environment.
\end{abstract}

\section{Hosted file}

Manuscript.pdf available at https://authorea.com/users/408725/articles/518624-biochar-apotential-soil-ameliorant-for-sustainable-land-agriculture-and-environmental-development

\section{Hosted file}

Table 1.pdf available at https://authorea.com/users/408725/articles/518624-biochar-apotential-soil-ameliorant-for-sustainable-land-agriculture-and-environmental-development 